\title{
Case Report \\ “The Clock Is Ticking": The Timely Management of a Painful Skin Rash in a Seventy-Year-Old Woman
}

\author{
Susan Thomas, ${ }^{1}$ Folashade Omole, ${ }^{1}$ Vijaykumar G. Patel, ${ }^{2}$ and Michelle L. Nichols ${ }^{1}$ \\ ${ }^{1}$ Department of Family Medicine, Morehouse School of Medicine, 1513 East Cleveland Avenue, Building 100, Suite 300A, \\ Atlanta, GA 30344, USA \\ ${ }^{2}$ Department of Surgery, Morehouse School of Medicine, 1513 East Cleveland Avenue, Building 100, Suite 300A, \\ Atlanta, GA 30344, USA \\ Correspondence should be addressed to Folashade Omole; fomole@msm.edu
}

Received 22 September 2013; Revised 8 December 2013; Accepted 14 January 2014; Published 23 February 2014

Academic Editor: Jeannette Guarner

Copyright ( $\odot 2014$ Susan Thomas et al. This is an open access article distributed under the Creative Commons Attribution License, which permits unrestricted use, distribution, and reproduction in any medium, provided the original work is properly cited.

Necrotizing fasciitis is an uncommon but a potentially fatal condition and can affect any part of the body. Most patients have preexisting conditions that render them susceptible to infection, although etiology is unclear. Diagnosis is primarily clinical and is often delayed because of the unfamiliarity of the condition among clinicians. Management consists of immediate resuscitation, early surgical debridement, and administration of broad spectrum intravenous antibiotics. We report a case of a 70 year old woman who presented with a painful erythematous rash, was admitted as a case of cellulitis, later developed worsening of symptoms and septic shock, and was diagnosed as necrotizing fasciitis.

\section{Introduction}

Necrotizing fasciitis is an uncommon disease that results in morbidity and mortality if not treated early. Most patients who develop necrotizing fasciitis have preexisting conditions that render them susceptible to infection. Advanced age, diabetes mellitus, chronic renal failure, peripheral vascular disease, and drug misuse seem to be risk factors [1]. We report a case of necrotizing fasciitis in a diabetic patient who presented with redness and pain of right thigh.

\section{Case Report}

A 70-year-old woman with a history of noninsulin requiring diabetes mellitus, hypertension, hyperlipidemia, and chronic atrial fibrillation on warfarin therapy, returning home from a cruise to Bahamas, presented to the emergency room. She reported a one-day history of a 10/10 pain in right thigh and leg, subjective fever, and nausea. Physical examination revealed blood pressure $133 / 89 \mathrm{~mm} \mathrm{Hg}$, heart rate $94 /$ minute, respiratory rate $18 /$ minute, and temperature $101.30 \mathrm{~F}$. Oxygen saturation was $96 \%$ on room air. There was marked erythema with induration of the skin involving the posterior thigh and leg along with the popliteal fossa measuring about $12 \mathrm{~cm}$ in length. Laboratory and radiological investigation revealed a white blood cell count of $19.7 / \mu \mathrm{L}$ with $85 \%$ neutrophils, D-dimer of 2.9 , and an international ratio (INR) of 3.16. Doppler ultrasound of the right lower extremity was negative for deep venous thrombosis. She was admitted with the diagnosis of cellulitis and started on intravenous clindamycin and fluids. On hospital day one, there was worsening of the lower extremity pain and erythema (Figures 1, 2, 3, and 4), with development of disseminated intravascular coagulation (DIC) and septic shock. Subsequent lab results showed sodium $144 \mathrm{mmol} / \mathrm{L}$ (millimoles/litre), potassium $4.2 \mathrm{mmol} / \mathrm{L}$, chloride $97 \mathrm{mmol} / \mathrm{L}$, and bicarbonate $12 \mathrm{mmol} / \mathrm{L}$. Blood glucose was $181 \mathrm{mg} / \mathrm{dL}$, and C-reactive protein (CRP) was elevated at $15.8 \mathrm{mg} / \mathrm{L}$. Urea was $30 \mathrm{mg} / \mathrm{dL}$ and creatinine $2.5 \mathrm{mg} / \mathrm{dL}$. Patient's hemoglobin and hematocrit were $9.2 \mathrm{~g} / \mathrm{dL}$ and $27.4 \%$, respectively. And other laboratory values were a lactic acid of $19.6 \mathrm{mmol} / \mathrm{L}$, and a prothrombin time of 61.7 seconds with an INR of 5.76. The Laboratory Risk Indicator for necrotizing fasciitis (LRINEC) score was 6 in the patient. She was transferred to intensive care unit (ICU), intubated, and started on vasopressors, along with penicillin, vancomycin, and zosyn (piperacillin and 


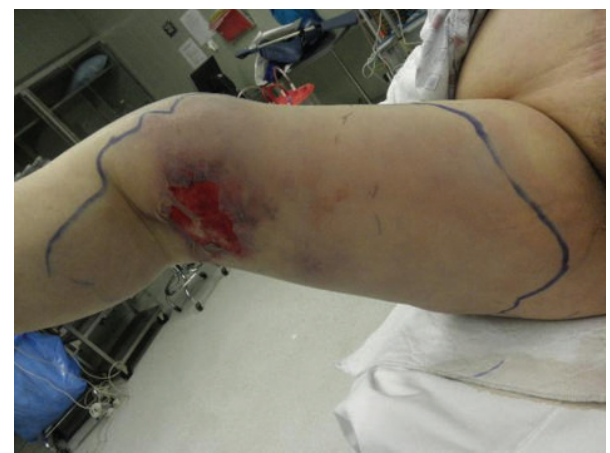

FIGURE 1: Preoperative photograph on the day of admission showing rapidly progressive painful extensive erythema, blistering, ulceration, edema, and skin necrosis of the right leg due to necrotizing soft tissue infection.

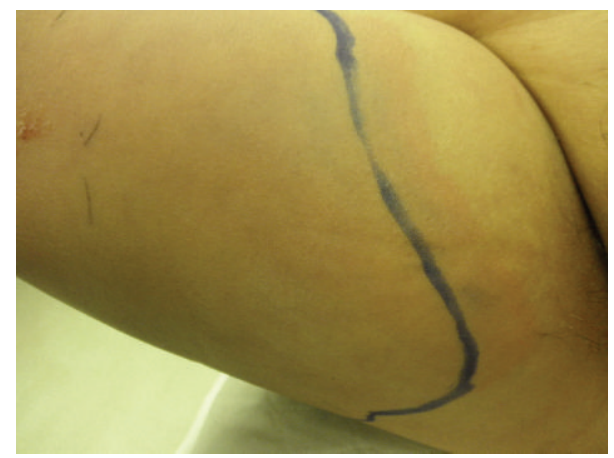

FIGURE 2: Photograph showing line of demarcation of erythema after admission and subsequent rapid progression of erythema within 1 hour. The rapid spread of necrotizing infection is facilitated by the enzymes and toxins produced by the organisms and is one of the hallmarks for clinical diagnosis.

tazobactam). She was resuscitated with 4 litres of normal saline, and during the course of her ICU admission, before and after debridement, she received a total of 13 units of packed red blood cells (PRBC), 9 units of fresh frozen plasma (FFP), and 4 units of platelets. Initial surgical debridement was done within six hours (see the figures) and two more over the next forty-eight hours. Patient was also hemodialyzed due to acute renal failure. Blood and wound cultures grew group A Streptococcus (Streptococcus pyogenes) sensitive to penicillin. The gross pathological specimen revealed wide excision of skin, subcutaneous tissue, and deep fascia down to the muscle from proximal thigh to mid-calf measuring 44 $\times 22 \times 2.5 \mathrm{~cm}$, with evidence of skin sloughage reddish yellow measuring $8 \times 6.5 \mathrm{~cm}$. With successful and early surgical debridement, appropriate antibiotic therapy, and other supportive treatments, patient's shock and DIC resolved. Patient received skin grafting at the surgical site. Tracheostomy was done due to difficulty to wean patient off the ventilator after two prolonged weeks of intubation; patient was transferred to a long-term care facility for prolonged ventilator care and rehabilitation.

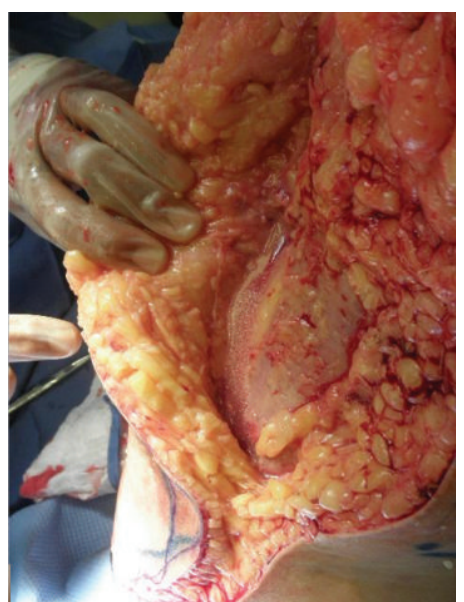

FIGURE 3: Intraoperative photograph showing deep necrotizing infection involving subcutaneous tissue along superficial and deep facial planes with watery purulent fluid adjacent to deep fascia and underlying muscles.

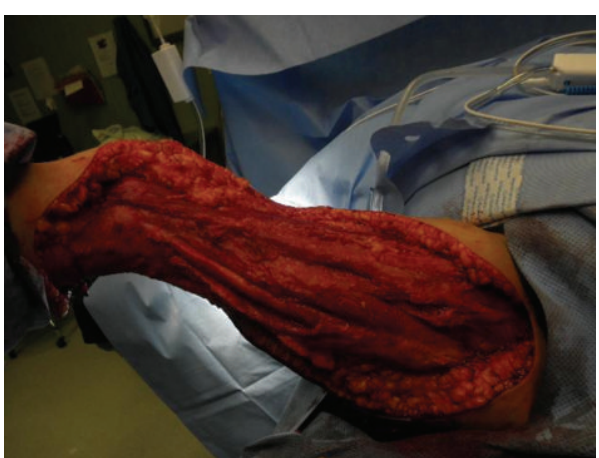

FIGURE 4: Intraoperative photograph showing aggressive surgical debridement of all necrotic and infected tissues involving the right leg.

\section{Discussion}

Necrotizing skin infections were first described by Jones in 1871, and "hospital gangrene" was the term used then [2]. Most patients who develop necrotizing fasciitis have preexisting conditions that render them susceptible to infection. Conditions such as advanced age, diabetes mellitus (as in our patient), chronic renal failure, peripheral vascular disease, and drug misuse seem to be risk factors [1]. However, the etiology of necrotizing fasciitis is not fully understood, and in many cases no identifiable cause can be found [3]. It occurs slightly more often in male patients [1].

3.1. Clinical Features. Necrotizing fasciitis can affect any part of the body, but the extremities, perineum, and the trunk are most commonly affected [4]. Most patients present with erythema, swelling, and pain in the affected site. Severe pain disproportionate to local findings, in association with systemic toxicity, should raise the suspicion of necrotizing fasciitis. 
TABLE 1: LRINEC scoring system to help discriminate between necrotizing and nonnecrotizing soft tissue infections [2].

\begin{tabular}{|c|c|}
\hline Value & LRINEC score, points \\
\hline \multicolumn{2}{|c|}{ C-reactive protein, $\mathrm{mg} / \mathrm{L}$} \\
\hline$<150$ & 0 \\
\hline$>150$ & 4 \\
\hline \multicolumn{2}{|c|}{ WBC count, cells $/ \mathrm{mm}^{3}$} \\
\hline$<15$ & 0 \\
\hline $15-25$ & 1 \\
\hline$>25$ & 2 \\
\hline \multicolumn{2}{|c|}{ Hemoglobin level, g/dL } \\
\hline$>13.5$ & 0 \\
\hline $11-13.5$ & 1 \\
\hline$<11$ & 2 \\
\hline \multicolumn{2}{|c|}{ Sodium level, mmol/L } \\
\hline$\geq 135$ & 0 \\
\hline$<135$ & 2 \\
\hline \multicolumn{2}{|c|}{ Creatinine level, mg/dL } \\
\hline$\leq 1.6$ & 0 \\
\hline$>1.6$ & 2 \\
\hline \multicolumn{2}{|c|}{ Glucose level, mg/dL } \\
\hline$\leq 180$ & 0 \\
\hline$>180$ & 1 \\
\hline
\end{tabular}

Goldstein et al. [2].

3.2. Diagnosis. The findings of crepitus and soft tissue air on plain radiograph are seen in $37 \%$ and $57 \%$ of patients, respectively [1]. Even though it is considered pathognomonic for the disease, the absence of crepitus should not exclude the diagnosis and therefore having a great index of suspicion is paramount $[1,4]$. CT and MRI have limited roles and may delay treatment [5]. Other findings that are common in necrotizing fasciitis include leukocytosis, elevated glucose, urea, and creatinine levels. Hypoalbuminemia, acidosis, and an altered coagulation profile may also be present $[1,3$, $4,6]$. Most studies have shown that necrotizing fasciitis is polymicrobial, in nature, with Streptococcus being the most common causative organism $[1,3,6]$, although a review study revealed that group A streptococci (GAS) was isolated in only $15 \%$ of individuals with necrotizing fasciitis [7]. There has been an emergence of toxic shock strains of Streptococcus (group A $\beta$ hemolytic streptococci) leading to fasciitis with organ dysfunction $[1,8]$. This virulent organism received much press coverage as the "flesh eating bacterium." Table 1 shows the Laboratory Risk Indicator for Necrotizing Fasciitis (LRINEC) score, this is used to risk stratify patients (Table 2), that is, heighten the suspicion of NF to differentiate it from other skin and soft tissue infections [2]. A score of 6 and above is considered to be of intermediate or high risk and has a positive predictive value of $92 \%$ and a negative predictive value of $96 \%$, and therefore clinical suspicion should still trump the LRINEC score $[2,9,10]$. The "finger test" which is characterized by lack of resistance to finger dissection in normally adherent tissues done under local or general anesthesia to assess the need for surgical debridement is
TABLE 2: Risk stratification of the LRINEC score according to the likelihood of necrotizing soft tissue infection (NSTI) [2].

\begin{tabular}{lcc}
\hline Risk category & LRINEC score, points & Probability of NSTI, \% \\
\hline Low & $\leq 5$ & $<50$ \\
Intermediate & $6-7$ & $50-75$ \\
High & $\geq 8$ & $>75$ \\
\hline
\end{tabular}

Goldstein et al. [2].

a quick and easy test [2]. Macroscopic findings during surgical exploration include gray necrotic tissue, lack of bleeding, thrombosed vessels, "dishwater" pus, noncontracting muscle, and a positive "finger test" result.

3.3. Management. The core of the treatment is early surgical debridement, which significantly improves mortality compared with delayed surgery [6]. Delaying surgical debridement more than 24 hours of admission was found to be associated with a mortality of $25 \%$ versus $6 \%$ when surgical debridement is done early $[11,12]$. Further surgical exploration 24-48 hours later is mandatory to ensure that the infectious process has not extended [8]. Resuscitative and supportive care is also paramount. Principles of Treatment $[2,8,13]$ are as follows:

$$
\begin{aligned}
& \text { adequate fluid resuscitation, } \\
& \text { correction of electrolyte and acid-base abnormalities, } \\
& \text { rapid initiation of antimicrobial therapy, } \\
& \text { immediate surgical debridement of necrotic tissues, } \\
& \text { support for failing organs. }
\end{aligned}
$$

\section{Conclusion}

Necrotizing fasciitis is an uncommon, but life threatening, condition with a high associated mortality and morbidity. Prompt diagnosis is the key to a favorable outcome. The LRINEC score is useful, but the diagnosis is still primarily a clinical one, and suspicion alone warrants early surgical referral.

\section{Conflict of Interests}

The authors declare that there is no conflict of interests regarding the publication of this paper.

\section{Acknowledgment}

The authors want to thank Dr. Karim Godamunne who was the admitting physician.

\section{References}

[1] D. C. Elliott, J. A. Kufera, and R. A. M. Myers, "Necrotizing soft tissue infections: risk factors for mortality and strategies for management," Annals of Surgery, vol. 224, no. 5, pp. 672-683, 1996. 
[2] E. J. Goldstein, D. A. Anaya, and E. P. Dellinger, "Necrotizing soft-tissue infection: diagnosis and management," Clinical Infectious Diseases, vol. 44, no. 5, pp. 705-710, 2007.

[3] G. Singh, S. K. Sinha, S. Adhikary, K. S. Babu, P. Ray, and S. K. Khanna, "Necrotising infections of soft tissues-a clinical profile," European Journal of Surgery, vol. 168, no. 6, pp. 366$371,2002$.

[4] A. Golger, S. Ching, C. H. Goldsmith, R. A. Pennie, and J. R. Bain, "Mortality in patients with necrotizing fasciitis," Plastic and Reconstructive Surgery, vol. 119, no. 6, pp. 1803-1807, 2007.

[5] M. G. Wysoki, T. A. Santora, R. M. Shah, and A. C. Friedman, "Necrotizing fasciitis: CT characteristics," Radiology, vol. 203, no. 3, pp. 859-863, 1997.

[6] C. R. McHenry, J. J. Piotrowski, D. Petrinic et al., "Determinants of mortality for necrotizing soft-tissue infections," Annals of Surgery, vol. 221, no. 5, pp. 558-563, 1995.

[7] N. Eke, "Fournier's gangrene: a review of 1726 cases," British Journal of Surgery, vol. 87, no. 6, pp. 718-728, 2000.

[8] S. Hasham, P. Matteucci, P. R. W. Stanley, and N. B. Hart, "Necrotising fasciitis," British Medical Journal, vol. 330, no. 7495, pp. 830-833, 2005.

[9] C.-H. Wong, L.-W. Khin, K.-S. Heng, K.-C. Tan, and C.-O. Low, "The LRINEC (laboratory risk indicator for necrotizing fasciitis) score: a tool for distinguishing necrotizing fasciitis from other soft tissue infections," Critical Care Medicine, vol. 32, no. 7, pp. 1535-1541, 2004.

[10] M. P. Wilson and A. B. Schneir, "A case of necrotizing fasciitis with a LRINEC score of zero: clinical suspicion should trump scoring systems," The Journal of Emergency Medicine, vol. 44, no. 5, pp. 928-931, 2013.

[11] S. T. Lille, T. T. Sato, L. H. Engrav, H. Foy, and G. J. Jurkovich, "Necrotizing soft tissue infections: Obstacles in diagnosis," Journal of the American College of Surgeons, vol. 182, no. 1, pp. 7-11, 1996.

[12] C.-H. Wong, H.-C. Chang, S. Pasupathy, L.-W. Khin, J.-L. Tan, and C.-O. Low, "Necrotizing fasciitis: clinical presentation, microbiology, and determinants of mortality," Journal of Bone and Joint Surgery A, vol. 85, no. 8, pp. 1454-1460, 2003.

[13] T. Guo-Wei, J. O. Hwabejire, J. Min-Jie et al., "Multidisciplinary intensive care in extensive necrotizing fasciitis," Infection, vol. 41, no. 2, pp. 583-587, 2013. 


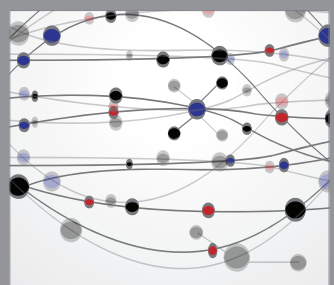

The Scientific World Journal
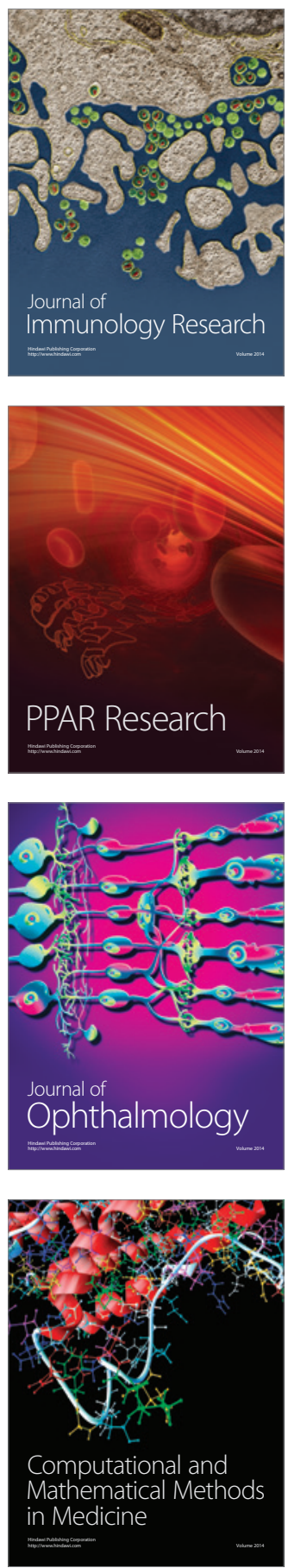

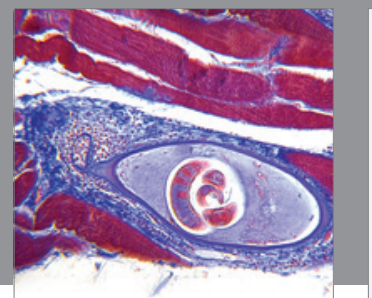

Gastroenterology

Research and Practice
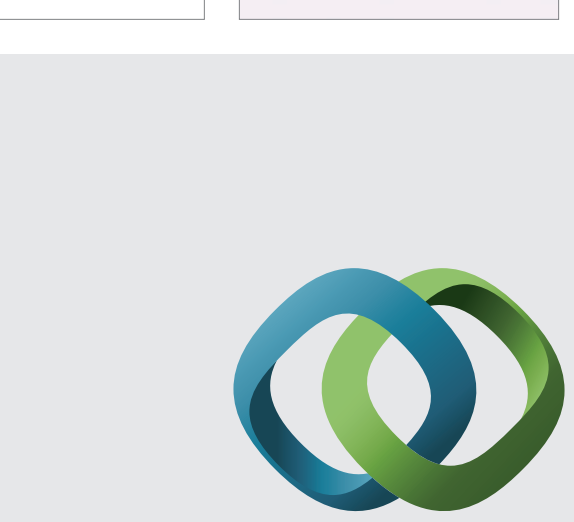

\section{Hindawi}

Submit your manuscripts at

http://www.hindawi.com
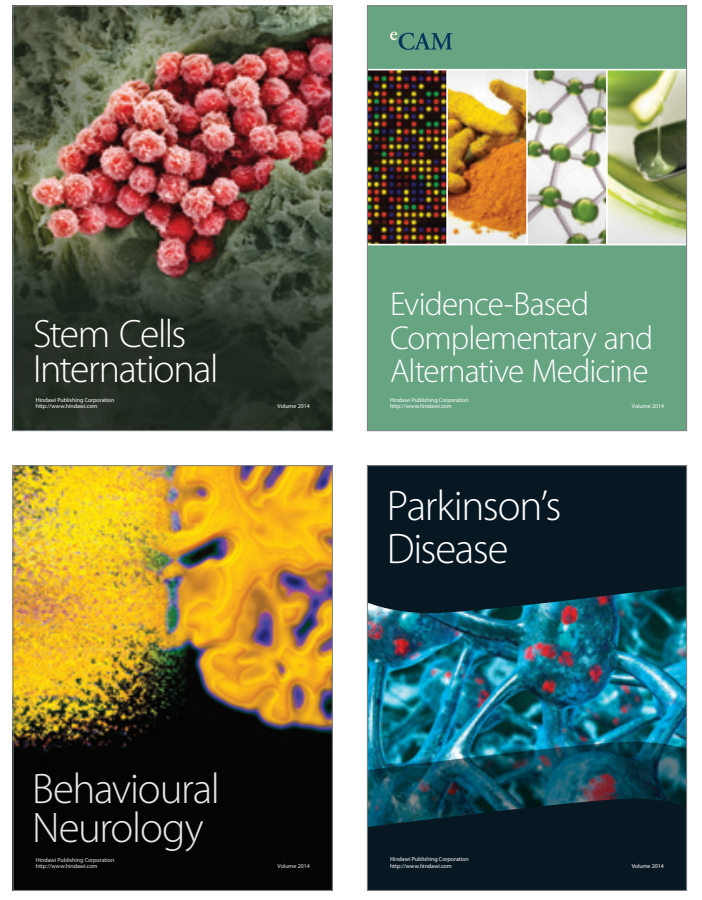
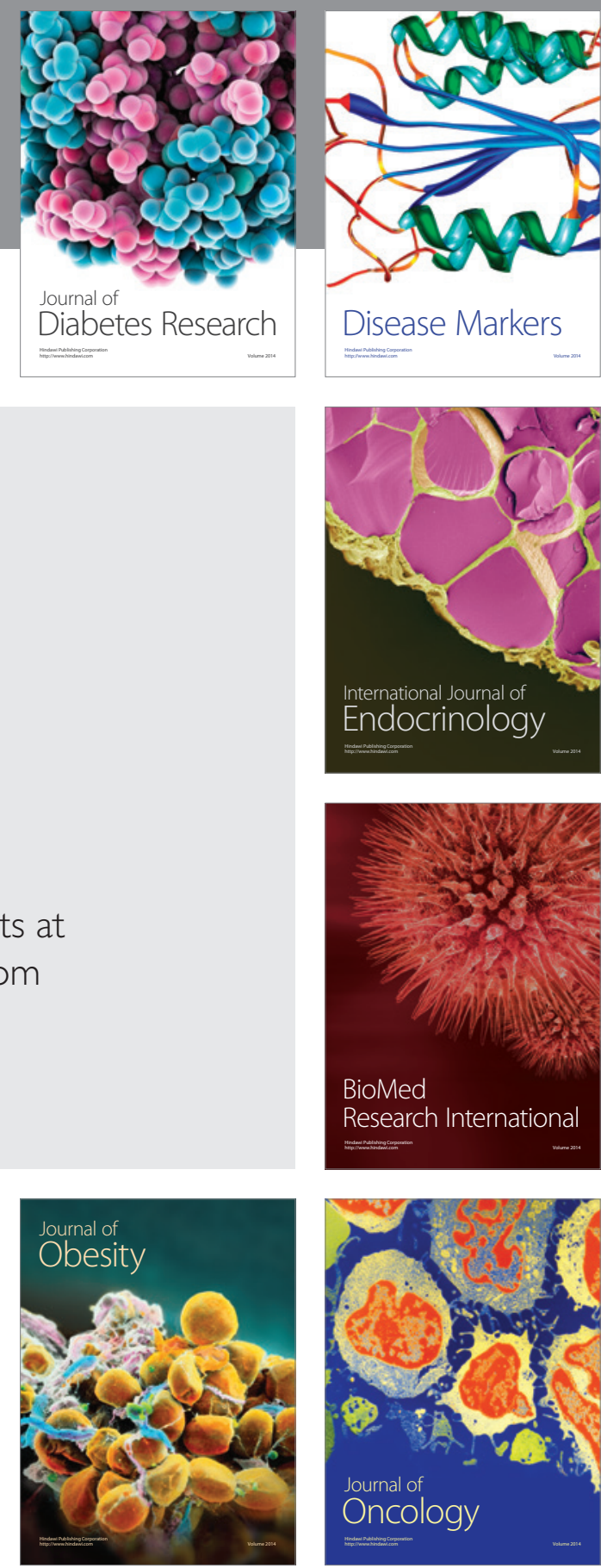

Disease Markers
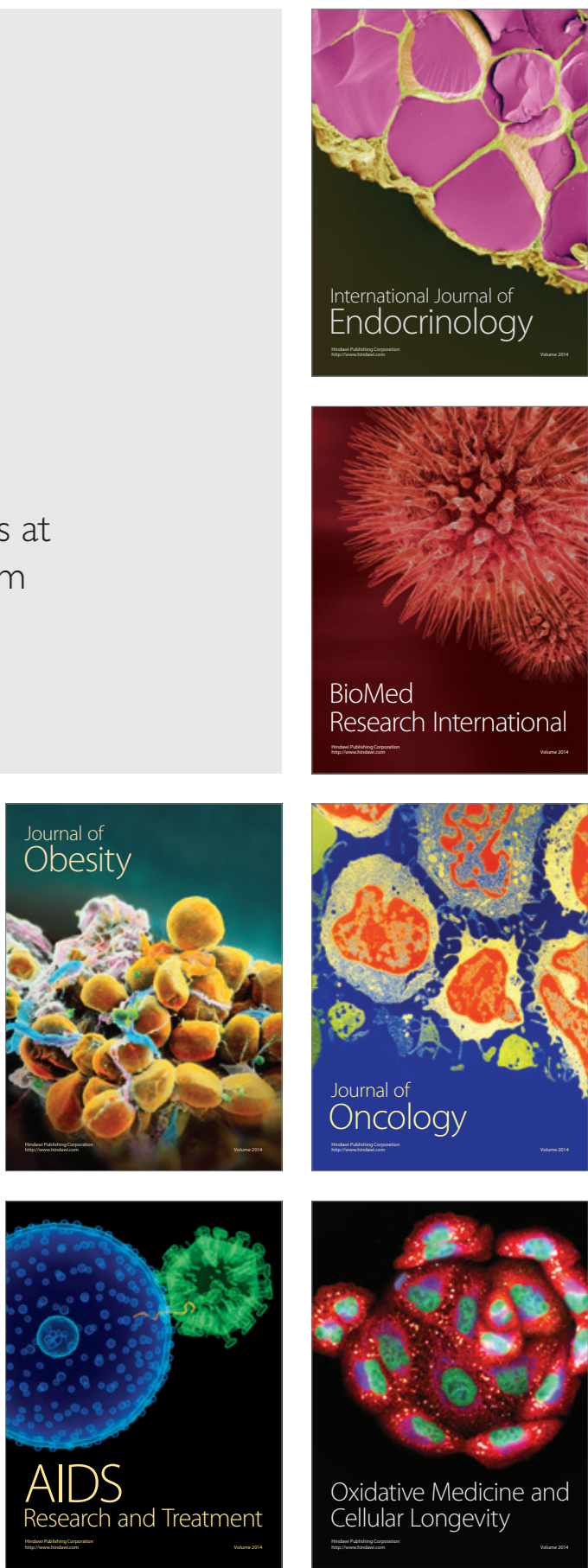